REMARKS ON

THE INFECTION OF DISEASES

AND ON THE

\section{CONTAGION OF TYPHUS.}

By Henry Jenner, M.D., F.L.S., \&c.

THE march of intellect during the forty years of the present century, has more rapidly advanced than for a great number of years, passed and gone for ever, and during this comparatively short space of time the great improvements and new discoveries which have been made in the various arts and sciences are astonishing and wonderful; nor has Nature been sparing of many of her before hidden secrets and mysteries to ingenious penetrations into the science of medicine and surgery, yet many of the most distinguished gentlemen of these professions appear at present to retrograde, by sup. posing that hitherto-considered pestilential diseases are not of a contagious or infectious nature, and that even the plague does not possess that property; they assert, that they consider the wise and salutary law of quarantine to be a farce, and that no infection can be received from typhus, cholera morbus, measles, scarlet-fever, influenza, or hooping-cough; but they have not yet ven. tured to go so far with respect to that great stumbling-block to their false doctrine, the small-pox, which, according to their doctrine, ought certainly to be included.

The fact appears to be that, with very few exceptions, all constitutions are always susceptible of small-pox, when not having previously had the disease, or been properly raccinated, but less so with respect to typhus and cholera morbus; and more especially when the infection is not much concentrated, but more diffused about the surrounding atmosphere to lessen its infla. ence; otherwise, woful would be the consequence, and many more persons would become afflicted with, or fall victims to, these sad diseases, than from the ravages of the small-pox before the introduction of vaccination, particularly taking into consideration, also, that persons are liable to repeated attacks of typhus.

The origin of typhus may be attributed to various causes. It may arise from the efflu. vium or stench of stagnated ditches, or obstructed drains and gutters; or from the foul air of close, crowded, flthy dwellings; or, perhaps, as supposed, it may be produced from an epidemic influence, if, at certain times and seasons, and in particular situations, the atmosphere be peculiarly conta. minated, which, by a different kind of contamination, may, possibly, then cause the different species of maladies which have been alluded to; but I know of none which are supposed to have epidemic origin, proceed from such causes as are stated, that cannot be communicated, by contagion or infection, to other persons, and be then car. ried on from them to others, in succession.

From observation and experience, the fact that typhus is contagious and infectious has for ages been established, and, by the general voice of the people, been proclaimed to be so. "Vox populi, est vox Dei." And I would ask, how that great and merciful man, Howard, becane afflicted with the disease to which he fell a victim?

In farther testimony of my opinion on infection, I will give a statement of the visita. tion of typhus which occurred last year at Hamfield, in this neigh bourhood.

Mr. William Ponting, a respectable farmer, who for many years occupied the extensive farm of Hamfield, in a liealthy situation, near the River Severn, in the parish of Berkeley, had one of his daughters, Miss Anne Ponting, married to Mr. Thomas Ashton, of Great Torrington, in Devonshire, where they resided. A servant, who had the care of their child eight months old, became ill with typhus, by visiting a female neighbour whilst afflicted with that disease. Mrs. Ashton came away to her relatives at Hamfield with the child and Miss Ashton, her husband's sister, as the servaut could not accompany them.

On their journey the child sickened with the disease, very soon after leaving home.

In about a fortnight after, Mrs. Ashton was herself very severely seized with it, and soon after died.

In about another fortnight Samuel Wood* man, a workman, became ill, and went home, a mile and a half distant, and soon after died also.

He had a son and a daughter who resided in the same cottage with him. The son became infected.

Then, also, the daughter, who had waited on them, and was their nurse, but they both recovered.

At about this time Mr. Ponting's son, Mr. John Ponting, became severely afflicted with it.

So, also, did another of the workmen, James Watts, whose residence is more than two miles distant from Hamfield, in a differ. ent direction from that of Samuel Woodman.

His wife attended and nursed him there, and she caught the disease.

So, also, did their daughter, but they all recovered, though the man was for several weeks in a state of great danger, and suffered extremely.

Another of Mr. Ponting's sons, Mr. Charles Ponting, after a short time from the attack of his brother, became very severely afflicted with the disease, and it was long before he recovered.

Two more of his sisters, Miss Fanny and Miss Annie Ponting, at about the same time, 
became ill, but they both had the disease slightly.

And now fell ill with it Mr. Ponting him. self, the disease in a short time proving fatal.

Finally, Mr. Edwin Foxwell, a nephew of Mrs. Ponting, who had lately resided at Mr. Ashton's, in about a fortuight after leaving Hamfield became ill with typhus.

Berkeley, Gloucestershire, 1840.

\section{DIVISION OF THE STERNO.CLEIDO. MASTOID MUSCLE}

FOR THE

\section{CURE OF WRY.NECK.}

\section{To the Editor of ThE Lancet.}

Sir:-Allow me to send you two sketches, representing the appearances of a gentleman before and after the division of the sternocleido-mastoid muscle.

Mr. Fred. Ward, æt. 21, the san of a weal thy Lincolnshire brewer, was born with wry-neck, and, being anxious to be relieved from the deformity, he consulted me on Thursday evening, Oct. 2znd; after proposing an operation, to which he consented, I divided the contracted muscle on the following morning.

After ascertaining the outline of, $I$ passed the knife under the tendinous portion of the muscle, and then turned the cutting edge of the knife towards the muscle, in order to divide it, without wounding the skin; the division of the tendon was announced by loud cracking sounds, such (according to the patient's statement) as might be produced by breaking sticks across the knee. I have divided the tendo Achillis for talipes, but its clicking is very different from the sound I an describing. The operation scarcely occupied a quarter of a minute, and not more than two or three drops of blood flowed from the small puncture; the patient scarcely felt the introduction of the knife, but the most excruciating pains followed the division of the tendon. When the mus. cle was divided, it sprang upwards with great violence, and appeared to tear away bands of cellular nembrane, which connected it with adjacent muscles. Upon each contraction of the muscle, the counterance gave evidence of the most acute suffering. When the division of the tendon was effected, the distorted side of the neck bobbed up, like an autumaton figure, when acted upon by machinery, suddenly put into motion. The small puncture made to introduce the knife healed on the following day, and the patient was able to resume his business three days after the operation.

On the day following the operation, $I$ placed a strap around the head, and another under the axilla, which buckled to a strap from the head-strap, so that I could use considerable power in bringing the head to the left side; but, I think, that there is not much occasion now for the strapping, as the patient can move his head in all directions, and without effort keep the head in a natural position. I am, Sir, yours, \&c.

Boston, Oct. 30, 1840.

$$
\text { F. SNaIth, M.D. }
$$
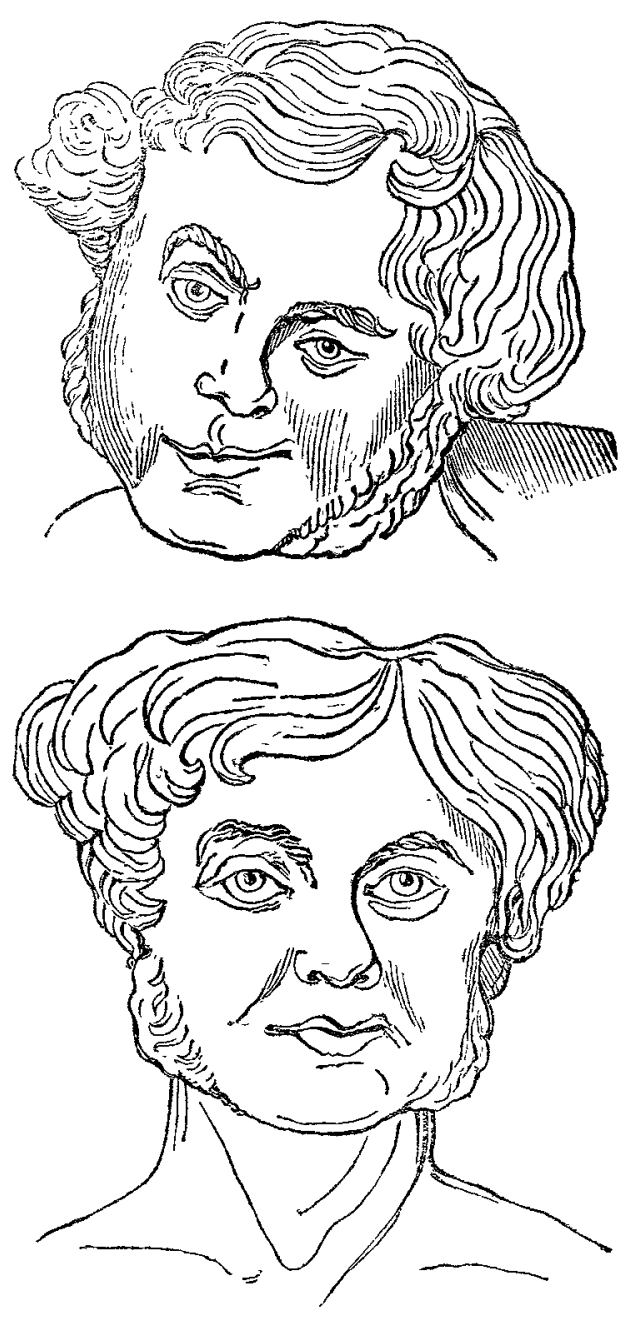

CONTAGION OF ASIATIC CHOLERA.

\section{To the Editor of The LAncet.}

SIR :-In your last No. (3) there is a case given of "Asiatic cholera," by Mr. Gosse, upon which I beg to make a few remarks. From the history of the complaint, there can be no doubt as to the nature of the disease, I myself having seen numerous isolated cases since cholera was so prevalent in this conntry, but more particularly four, two of which recovered and two died; and, moreover, I entirely concur in your correspondent's opinion, that "Asiatic cholera may be regarded as incidental to this country " but there are two points connected with his communica- 